\title{
PENGEMBANGAN SISTEM INFORMASI BERBASIS WEB UNTUK PT. XYZ
}

\author{
Fictor Benny \\ Program Studi Magister Manajemen Universitas Tarumanagara \\ fictorbennyku@outlook.com \\ Rina Adi Kristianti \\ Program Studi Magister Manajemen Universitas Tarumanagara
}

\begin{abstract}
This Journal discusses about the function of Information System useful for the company in facing the problems associated with the relationship between the company with the customer causing the number of miss communication so that affects all divisions and also relationships with customers. Customers in this journal is a distributor that can be said as customer level one or supplier of goods. In the journal problems obtained by approaching fish bone. What is then known that in need is an application that can be a liaison in both of these things.
\end{abstract}

Keywords: Information System, fish bone, problems associated

\section{PENDAHULUAN}

\section{Latar Belakang}

Di jaman yang semakin modern peran sistem informasi sangatlah penting dalam proses bisnis dan usaha. Dengan system informasi yang tepat maka proses pengambilan keputusan dapat semakin muda. Hal inilah yang menyebabkan keputusan untuk memilih sistem informasi yang akan digunakan juga merupakan keputusan yang sangat penting bagi strategi untuk meningkatkan kemajuan bisnis.

Saat ini hampir semua perusahaan menyadari perkembangan suatu sistem berkaitan erat dengan kemampuan dan ketersediaan fasilitas yang dimiliki perusahaan untuk menghasilkan suatu informasi. Sehingga kesalahan dalam pemilihan sistem informasi dapat mengakibatkan proses bisnis yang ada menjadi terhambat dan menyebabkan terjadi kerugian dalam berbagai bentuk bagi badan usaha tersebut, misalnya kehilangan waktu dan kehilangan peluang pendapatan di masa yang akan datang.

Dalam journal ini penulis bertujuan membantu masalah dari PT.XYZ dalam masalah pemilihan system yang tepat untuk menghadapi masalah komunikasi yang terjadi pada perusahaan ini karena kurangnya informasi yang ada.

PT.XYZ merupakan salah satu perushaaan yang berkecimpung dalam industri makanan dengan product permen dan ice dengan 5 cabang di Indonesia dan 3 cabang di luar negeri. PT.XYZ sendiri merupakan perusahaan yang membuat sekaligus mendistribusikan barangnya sendiri ke pada penyalur-penyalur (Distributor) besar di berbagai pulau di indonesia. Saat ini dalam sehari lebih dari 50 kontainer keluar dari pabrik untuk di distribusikan ke semua titik di Indonesia.

PT.XYZ merupakan perusahaan yang sudah lama bermain dalam bidang permen dan ice. Namun dengan semakin besar perusahaan maka akan semakin tinggi kebutuhan dalam pengembahan teknologi yang dibutuhkannya dalam menghadapi masalah yang ada. Salah 
masalah yang di hadapi oleh PT.XYZ yang ada saat ini adalah hubungan komunikasi yang antara sales dan distributor yang sering terjadi miss komunikasi.

Hal ini menyebabkan barang yang di pesan sering kali tidak dapat di kirim karena ketidak adanya stock barang atau barang yang di kirim tidak sesuai dengan permintaan sehingga di akhir bulan sering kali menjadi kendalam dalam mencocokkan item dan jumlah barang terkirim ke distributor. Masalah ini juga menimbulkan masalah bagi pihak pihak diinternal di dalam perusahaan yang menyebabkan banyaknya biaya-biaya tambahan yang terjadi salah satunya adalah cost untuk lembur agar dapat memenuhi stock yang di perlukan.

Menurut Wilkinson dan Cerullo (1997) hampir semua perusahaan bisnis menggunakan mikrokomputer dan komputer induk atau Server sebagai bagian yang saling terintegrasi dalam sistem informasi. Ditambah dengan adanya Internet sebagai salah satu bagian perkembangan teknologi yang saat ini marak digunakan oleh banyak perusahaan bisnis sebagai salah satu bagian dari strategi untuk memasarkan atau memberikan informasiinformasi terkait pada pihak tertentu. Dari masalah ini PT.XYZ berusaha mencoba mencari solusi terbaik untuk mengadapi ancaman yang ada dari masalah komunikasi ini.

\section{Pokok Masalah}

Masalah yang di teliti dalam penelitian ini adalah sebagai berikut:

1. Dampak apa saja yang dapat diberikan dengan adanya peningkatan Informasi dan Teknologi terhadap PT. XYZ?

2. Bagaimana agar PT.XYZ dapat meningkatkan efektifitas team marketing menggunakan Informasi dan Teknologi yang sudah ada saat ini dalam rangkah meningkatkan penjualan?

3. Teknologi dan Informasi seperti apa yang dibutuh kan PT.XYZ agar dapat mengembakan usahanya lebih maju?

\section{Tujuan, Ruang Lingkup, dan Manfaat Penelitian}

\section{Tujuan Penelitian}

Penulisan ini bertujuan untuk membantu mengembakan system informasi untuk menjawab pokok masalah yang dihadapi oleh PT XYZ dalam memberikan informasi dan mengatur strategi dalam memajukan perusahaan serta mengatasi masalah komunikasi.

\section{Ruang Lingkup Penelitian} PT.XYZ

Penelitian hanya di dasarkan pada data-data yang transaksi dan penjualan di

\section{Manfaat Penelitian}

Bagi Perusahaan:

Diharapkan perusahaan mendapatkan masukan untuk pembuatan system untuk menjawab permasalahan yang dihadapi perusahaan.

Bagi pihak lain:

Diharapkan penelitian ini dapat bermanfaat bagi pihak lain untuk mencoba mengembangkan system informasi untuk menghadapai kasus-kasus yang sejenis.

\section{TELAAH KEPUSTAKAAN SISTEM}

Sistem adalah sekelompok komponen dan elemen yang digabungkan menjadi satu untuk mencapai tujuan tertentu. Sistem berasal dari bahasa Latin (systēma) dan bahasa 
Yunani (sustèma) adalah suatu kesatuan yang terdiri komponen atau elemen yang dihubungkan bersama untuk memudahkan aliran informasi, materi atau energi untuk mencapai suatu tujuan. Istilah ini sering dipergunakan untuk menggambarkan suatu set entitas yang berinteraksi, di mana suatu model matematika seringkali bisa dibuat.

Menurut ogianto (2005:2), Sistem adalah kumpulan dari elemen-elemen yang berinteraksi untuk mencapai suatu tujuan tertentu. Sistem ini menggambarkan suatu kejadiankejadian dan kesatuan yang nyata, seperti tempat, benda dan orang-orang yang betul-betul ada dan terjadi.

Menurut ludwig von bertalanffy (1968) Sistem merupakan seperangkat unsur yang saling terikat dalam suatu antar relasi diantara unsur-unsur tersebut dengan lingkungan.

Menurut anatol rapoport (1986) Sistem adalah suatu kumpulan kesatuan dan perangkat hubungan satu sama lain.

Menurut O’Brien (2003) sistem adalah sebuah kelompok yang terintegrasi dan bekerja sama untuk mencapai tujuan yang sama dengan menerima masukan (input) dan menghasilkan keluaran (output) dalam sebuah proses transformasi yang terorganisir dengan baik.

\section{Komunikasi}

Komunikasi adalah "suatu proses dimana seseorang atau beberapa orang, kelompok, organisasi, dan masyarakat menciptakan, dan menggunakan informasi agar terhubung dengan lingkungan dan orang lain" (Ruben Brent D dan Lea P Stewart, 2006).

Komunikasi merupakan hal yang sangat penting bagi kehidupan sehari-hari maupun dalam berorganisasi. Kemampuan berkomunikasi yang baik merupakan syarat utama dalam berorganisasi karena dengan komunikasi yang baik, kegiatan organisasi dapat berjalan dengan baik, lancar dan sesuai tujuan organisasi tersebut.

Komunikasi dikatakan efektif bila orang berhasil menyampaikan apa yang dimaksudkannya. Sebenarnya, ini hanya salah satu ukuran bagi efektivitas komunikasi. Secara umum, komunikasi dinilai efektif bila rangsangan yang disampaikan dan yang dimaksudkan oleh pengirim atau sumber, berkaitan erat dengan ragsangan yang ditangkap dan dipahami oleh penerima (Stewart L Tubbs \& Sylvia Moss, 2000).

Komunikasi sendiri bukan hanya ilmu pengetahuan, tapi juga seni bergaul. Agar kita dapat berkomunikasi efektif, kita dituntut tidak hanya memahami prosesnya, tapi juga mampu menerapkan pengetahuan kita secara kreatif (Kincaid dan Schramm, 1977:2). Komunikasi yang efektif adalah komunikasi dalam makna yang distimulasikan serupa atau sama dengan yang dimaksudkan komunikator. Pendeknya, komunikasi efektif adalah makna bersama (Verderber, 1978:7).

Komunikasi merupakan bagian dalam membangun iklim organisasi, yang berdampak kepada membangun budaya organisasi seperti nilai dan kepercayaan yang manjadi titik pusat organisasi. Budaya organisasi merupakan bagian yang tidak terpisahkan dari lingkungan internal organisasi karena keragaman budaya yang ada dalam suatu organisasi sama banyaknya dengan jumlah individu yang ada dalam organisasi. Umumnya budaya organanisasi sangat dipengaruhi oleh lingkungan eksternal organisasi. Suatu organisasi memerlukan satu budaya yang merupakan kumpulan persepsi secara umum dari seluruh karyawan sebagai anggota organisasi, yang akan dijadikan sebagai suatu system yang menggabungkan beberapa pengertian yang secara eksplisit dianggap sebagai definisi budaya organisasi. (Rahmi Yuliana, 2012).

\section{Teknologi Informasi dan Komunikasi}

terdiri dari dua aspek yaitu teknologi informasi dan teknologi komunikasi. Syam (Muhtadi, t.t:4) mendefinisikan teknologi informasi sebagai ilmu yang diperlukan untuk memanage informasi agar dapat ditelusuri kembali dengan mudah dan akurat. Sedangkan 
teknologi komunikasi menurut Mahmun (t.t:2) mengatakan bahwa teknologi komunikasi adalah teknologi yang berkaitan dengan cara menyampaikan data dan informasi.

Menurut Martin (Zulfa, 2010:3), teknologi informasi dan komunikasi yaitu semua bentuk teknologi yang terlibat dalam pengumpulan, memanipulasi, komunikasi, presentasi dan menggunakan data (data yang ditransformasi menjadi informasi).

\section{Teknologi Informasi dan Komunikasi dalam Sistem Informasi Manajemen}

teknologi komunikasi dan informasi merupakan sarana yang dapat digunakan untuk mengumpulkan atau menyediakan informasi yang dibutuhkan organisasi dengan akurat dan tanpa menghabiskan banyak waktu sehingga lebih mempercepat kinerja organisasi. Sedangkan Sistem Informasi Manajemen (SIM) berguna bagi organisasi dalam menyediakan informasi-informasi yang dapat digunakan sebagai bahan pertimbangan oleh pimpinan dalam pengambilan keputusan.

Maka pemanfaatan teknologi informasi dan komunikasi dalam sistem informasi manajemen akan mendukung aliran informasi berjalan dengan cepat dan akurat. Kemudahan yang ada ini akan mengakibatkan SIM menjadi lebih efisien.

\section{FISHBONE DIAGRAM METODE}

Metode Fishbone Diagram adalah suatu metode berbentuk tulang ikan sering juga disebut Cause and Effect diagram atau Ishikawa Diagaram diperkenalkan oleh Dr. Kaoru Ishikawa, seorang ahli pengendalian kualitas dari Jepang, sebagai satu dari tujuh alat kualitas dasar ( 7 basic quality tools). Fishbone diagram digunakan ketika kita ingin mengidentifikasi kemungkinan penyebab masalah dan terutama ketika sebuah team cenderung jatuh berpikir pada rutinitas (Tague, 2005, p. 247).

Suatu tindakan dan langkah improvement akan lebih mudah dilakukan jika masalah dan akar penyebab masalah sudah ditemukan. Manfaat fishbone diagram ini sebagai alat bantu untuk menemukan akar penyebab masalah secara user friendly, tools yang user friendly disukai orang-orang dan dapat digunakan dengan mudah. Fishbone diagram akan mengidentifikasi berbagai sebab potensial dari satu efek atau masalah, dan menganalisis masalah tersebut melalui sesi brainstorming. Masalah akan dipecah menjadi sejumlah kategori yang berkaitan, mencakup manusia, material, mesin, prosedur, kebijakan, dan sebagainya. Setiap kategori mempunyai sebab-sebab yang perlu diuraikan melalui sesi brainstorming.

Langkah-langkah yang diperlukan untuk membuat Cause and Effect Diagram :

1. Berikanlah Judul, Tanggal, Nama Produk, Nama Proses dan daftar nama Partisipan

2. Tentukan Pernyataan Permasalahan yang akan diselesaikan

3. Gambarkan Kepala Ikan sebagai tempat untuk menuliskan Akibat (Effect)

4. Tuliskan Pernyataan permasalahan tersebut di kepala Ikan sebagai Akibat (effect) dari penyebab-penyebab.

5. Gambarkan Tulang Belakang Ikan dan Tulang-tulang Besar Ikan

6. Tuliskan Faktor-faktor penyebab utama yang mempengaruhi kualitas di Tulang Besar Ikan.

7. Tuliskan penyebab-penyebab sekunder berdasarkan kategori Faktor penyebab Utama dan tuliskan di Tulang-tulang yang berukuran sedang

8. Tuliskan lagi penyebab-penyebab yang lebih details yang mempengaruhi penyebab sekunder kemudian gambarkan tulang-tulang yang berukuran lebih kecil lagi.

9. Tentukanlah faktor-faktor penyebab tersebut yang memang memiliki pengaruh nyata terdapat Kualitas kemudian berikanlah tanda di faktor-faktor penyebab tersebut.

Hal yang perlu diperhatikan dalam membuat Cause and Effect Diagram :

1. Setelah suatu masalah atau suatu situasi telah ditetapkan untuk dibahas lebih lanjut, tanyakan "mengapa-mengapa" sampai menemukan akar penyebab permasalahannya. 
2. Jika masalah tersebut terdapat beberapa penyebab potensial, maka kita harus meng-analisis setiap penyebab tersebut.

\section{METODE PENELITIAN}

\section{Jenis \& Periode Penelitian}

Jenis penelitian ini adalah penelitian deskriptif(descriptive research), yang bertujuan untuk menguraikan tentang peranan system informasi dalam membantu mengatasi masalah terutaman mengenai komunikasi secara external. Periode penelitian di mulai pada januari 2017 sampai dengan November 2017.

\section{Sumber dan Pengumpulan data}

Dalam Project ini sumber data dari penelitian adalah data analisa penjualan tahun 2016 sampai 2017 sebagai data pendukung masalah yang terjadi dan juga laporan keuangan sebagai alat bantu perusahaan dalam mendapatkan BEP sebagai landasan keputusan perusahaan dalam bidang keuangan.

Sebagai dasar awal penulis mencoba melakukan perbandingan berdasarkan laporan penjualan data tahun 2016 dan 2017 cut off bulan oktober 2017 dengan data diagaram sebagai berikut.

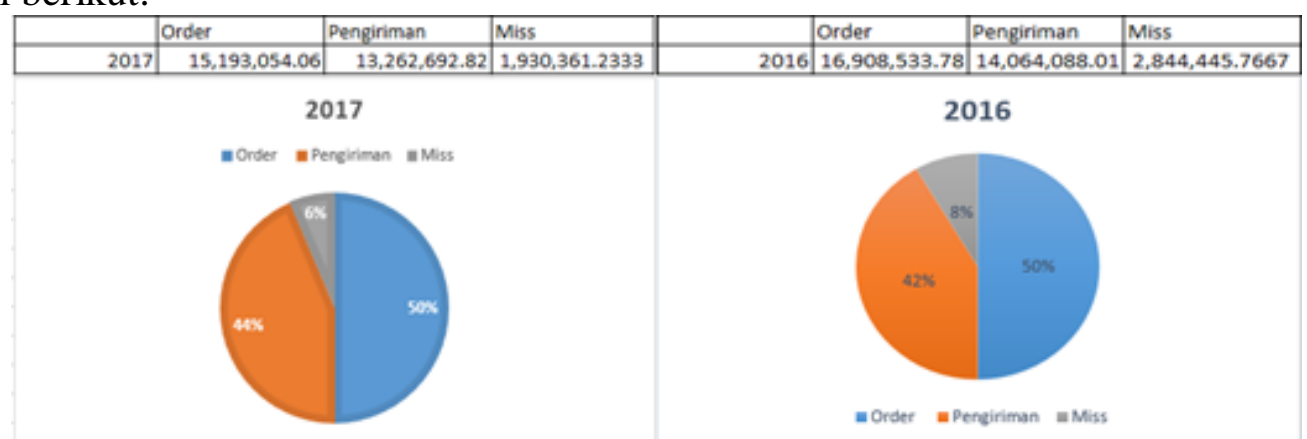

Dari data di atas penulis meliat adanya penurunan pada permintaan atau order yang di sebabkan karena banyak nya miss pengiriman di tahun sebelumnya. Dan mesti order sudah lebih rendah ternyata angka pada miss pengiriman di rasa masih cukup tinggi yang menyebabkan juga laba perusahaan menurun.

Selain dari data diatas penelitih menggunakan metode fish bone sebagai landasan untuk mencari akar masalah dari kasus yang dihadapi oleh PT.XYZ ini. Dari data2 serta wawancara yang dilakukan oleh penulis bagian-bagian yang terkait maka penulis menyimpulkan masalah yang terjadi dengan fish bone diagram sebagai berikut: 


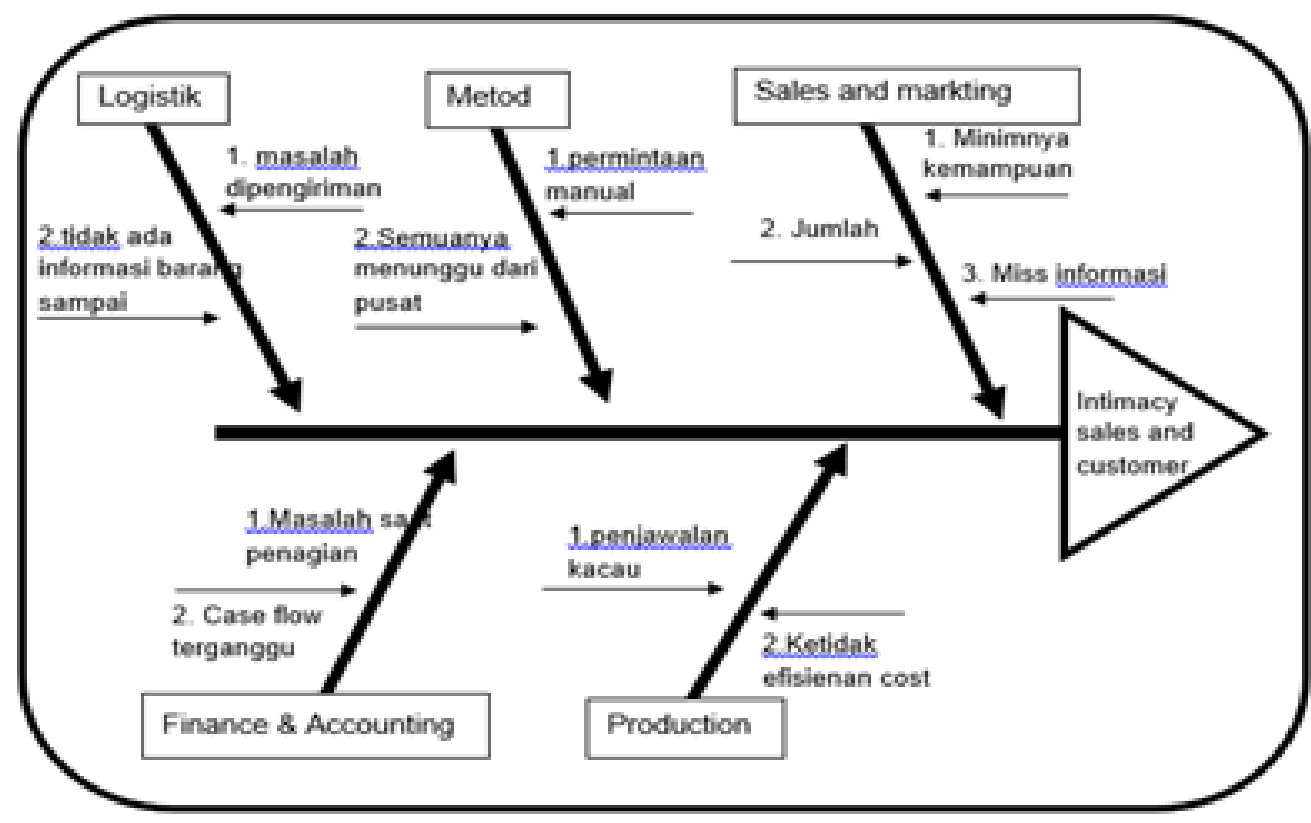

Secara detail penulis juga menerangkan masalah yang di hadapi oleh perusahaan dari diagram di atas sebagai berikut:

\begin{tabular}{|c|c|c|c|}
\hline & Root Cause Dominan & Alternatif Solusi & Final Solusi \\
\hline $\begin{array}{l}\text { Sales } \\
\text { marketing }\end{array}$ & $\begin{array}{l}\text { Minimnya informasi } \\
\text { sehingga tidak dapat } \\
\text { mengelola data }\end{array}$ & $\begin{array}{l}\text { Harus ada suatu applikasi } \\
\text { yang dapat mempermudah } \\
\text { sales menarik data } \\
\text { dimanapun }\end{array}$ & \multirow{5}{*}{$\begin{array}{lr}\text { Harus ada } & \text { suatu } \\
\text { applikasi online } & \text { yang } \\
\text { bisa di } & \text { akses } \\
\text { dimanapun oleh } & \text { sales } \\
\text { marketing } & \text { untuk } \\
\text { menjebatani } & \text { antara } \\
\text { perusahaan } & \text { dengan } \\
\text { Distributor sehingga } \\
\text { perusahanan } & \text { dapat } \\
\text { lebih mudah } & \text { dalam } \\
\text { mengatur } & \text { arus } \\
\text { castflow, penjadwalan } \\
\text { production r dan } \\
\text { pengecekan barang. }\end{array}$} \\
\hline Metode & $\begin{array}{l}\text { data disiapkan secara } \\
\text { manual oleh pusat }\end{array}$ & $\begin{array}{l}\text { mengubah olah manual } \\
\text { menjadi by system agar } \\
\text { lebih cepat }\end{array}$ & \\
\hline Losictic & $\begin{array}{l}\text { kurangnya informasi } \\
\text { pendukung untuk } \\
\text { mempermudah dalam } \\
\text { pengecekan barang }\end{array}$ & $\begin{array}{l}\text { harus ada informasi yang } \\
\text { bisa langsung di dapat saat } \\
\text { barang sampe ke distributor }\end{array}$ & \\
\hline $\begin{array}{l}\text { Finace \& } \\
\text { Acconting }\end{array}$ & $\begin{array}{l}\text { Caseflow terganggu } \\
\text { karena masalah dalam } \\
\text { penagian }\end{array}$ & $\begin{array}{l}\text { Dari awal harus sudah di } \\
\text { pastikan barang di terima } \\
\text { dalam jumlah yang sesuai } \\
\text { dan tanggal penerimaan } \\
\text { benar }\end{array}$ & \\
\hline Production & $\begin{array}{l}\text { production tidak efisien } \\
\text { karena penjadwalan yang } \\
\text { kacau akibat permintaan } \\
\text { mendadak }\end{array}$ & $\begin{array}{l}\text { Harus ada plan yang pasti } \\
\text { dari awal sehingga tidak ada } \\
\text { permintaan mendadak }\end{array}$ & \\
\hline
\end{tabular}


Dari masalah di atas penelitih menimpulkan bahwa masalah miss komunikasi yang terjadi pada PT. XYZ ini memberi dampak buruk hampir disemua bagian.

\section{SOLUSI}

Dari masalah di atas penelitih mencoba memberikan solusi dengan mencoba applikasi berbasi web application untuk menjadi penjebatan antara sales dan distributor sehingga mempermuda sales dalam mendapatkan data stock distributor dan distributor sendiri dapat langsung memesan kebutuhan barang jika stock sudah minimum.

Penulis menyimpulkan jika memang PT.XYZ bersedia melakukan project ini pada tahun pertama maka akan di jalankan di 6 location yang merupakan pusat penjualan paling tinggi dengan proses implementasi selama 2 bulan di setiap location. Hal ini dilakukan sebagai salah satu cara untuk dapat memperoleh hasil yang paling baik terutama juga untuk mempercepat arus BEP.

pelaksanaan akan di lakukan disetiap titik dimana diawali dengan kick off meeting dengan distributor sebagai pengenalan sekaligus tahap kerja sama. jika kerja sama diterima dengan baik maka diminggu selanjutnya kita dapat melakukan tahap Synchronize untuk menyamakan data dan pengkodean system ini dengan pengkodean dari pihak distributor. setelah data semua cocok maka di minggu selanjutnya kita akan mengadakan training selama 1 minggu dan dilanjutkan dengan Trial and error dalam pengerjaan project ini. jika selama 1 bulan trial and error dapat berjalan dengan baik makan di minggu ke8 kita dapan melakukan go live untuk titik tersebut.

\section{DAMPAK YANG DIALAMI}

Sebagai tambahan penulis mencoba memberikan simulasi arahan yang akan di dapat oleh PT.XYZ jika menjalankan project ini secara keuangan dan juga manfaat sebagai berikut:

\section{Secara Keuangan}

Dalam hal keuangan penelitih mencoba menganalisa laporan keuangan 2016 sebagai pembanding jika target pengiriman naik sebesar $1 \%$ pada tahun 2016 maka dapat di ketahui BEP perusahaan dari project ini adalah selama 0,47 tahun atau setara 5,6 bulan dan manfaat lebih akan dapat dirasakan di tahun-tahun berikutnya.

\section{Secara Manfaat}

Dalam hal manfaat penulis berangapan bahwa manfaat dari proyek ini akan dapat dirasakan oleh semua bagain adalah sebagai berikut:

1.Bagi Divisi Sales dan Marketing

- Sales dapat lebih mudah dan lebih update dalam mendapatkan informasi yang dibutuhkan seperti history pesanan dan orderan serta kapan orderan tersebut akan di kirim dan sampai

- Sales dapat lebih muda dalam menganalisa penjualan dan menentukan strategi untuk meningkatkan penjualan sekaligus melawan saingan.

\section{Bagi Distributor /Customer}

- Mempermudah dalam mendapatkan informasi barang yang di pesan dan sisa pesanan serta tagian yang harus di bayar

- Mempermudah dalam melakukan repeat order berdasarkan history pembelian

- Mempermudah dalam proses menklam barang bila ada orderan yang tidak sesuai pesanan sehingga dapat menotong tagian secara langsung atau diganti barang baru di next pengiriman.

3. Bagi Divisi Finance dan Acconting

- Dapat lebih muda dalam melakukan Proses invoice tanpa menunggu invoice sampe ke kantor dari expedisi 
- Mengurangi kesalahan dalam proses invoice karena barang tidak sesuai di akhir bulan karena info yang telat dari sales atau distributor.

4. Bagi Divisi Logistic

- Mempermuda dalam mengecek apakah barang sudah sampai ketujuan atau belum dan barang sesuai atau tidak dengan pesanan.

- $\quad$ Mempermuda dalam mengevaluasi expedisi yang di gudangan apakan bagus atau tidak.

- Mempermuda dalam menentukan penjadwalan sesuai history waktu dan hari pemesanan.

5. Bagi Divisi Production

- Mengurangi tingkat lembut jika ada orderan mendadak karena team sales telat memberikan informasi.

- $\quad$ Mempermuda dalam proses penjadwalan Produksi.

\section{KESIMPULAN}

Berdasarkan hasil analisis dengan mengunakan FishBone metode penulis dapat menarik beberapa sesimpulan saat ini masalah miss komunikasi yang di hadapi PT.XYZ berpengaruh terhadap semua bagian. Sehingga salah satu solusi yang bias di ambil adalah dengan project ini. Dimana project ini dinilai menguntungkan PT. XYZ baik secara keuangan maupun manfaat dalam internal perusahaan selain juga dengan adanya system ini maka PT.XYZ akan sayang dapat mengefektifitaskan team marketing mereka dengan data-data yang telah tersedia dan juga mengurangi miss komunikasi yang menyebabkan miss pada pengiriman dan merugihkan perusahaan.

\section{Saran}

Untuk dapat menangulangi masalah ini PT.XYZ membutuhkan suatu teknologi yang dapat membantu untuk mempermuda komunikasi dan mengurangi miss pada pengiriman barang yang dijawab dengan project ini. Namun juga harus diingat juga pentingnya komitmen dari masing-masing bagian karena project ini akan berhasil di lakukan jika di dukung secara penuh oleh semua anggota perusahaan karena hal ini menyangkut hubungan dengan pihak external. Selain itu juga perlu diadakan evaluasi lagi setelah pelaksanaan system ini untuk lebih dapat memahami posis dan tingkat miss komunikasi yang ada di perusahaan XYZ .

\section{DAFTAR PUSTAKA}

Tague, N.R (2005). The quality toolbox. (2th ed.). Milwaukee,Wisconsin:ASQ Quality Press Available.

Cerullo, Michael, J., Wilkinson, Joseph, W., Raval, Vasant., Wong-On-Wing, \& Bernard. (2000). Accounting Information System : Essential Concept and Applications. (4th Ed). Amerika : John Wiley and Sons, Inc.

Ruben Brent D dan Lea P Stewart. 2006. Communication and Human Behavior. United States: Allyn and Bacon.

Keith Davis, Human Relations at Work, (New York, San Francisco, Toronto, London: 1962).Hlm.15-19.

Kincaid, D. Lawrence, dan Wilbur Schramm. Azas-Azas Komunikasi Antar Manusia. Terj, Agus Setiadi (Jakarta: LP3ES, bekerja sama dengan East-West Communication Institute, Hawaii, 1978).

Tubbs, Stewart L \& Sylvia Moss. 2000. Human Communication ( Prinsip Prinsip dasar). Bandung : PT Remaja Rosdakarya. 
Robbins, S.P. 2001. Perilaku organisasi: Konsep, kontroversi, dan aplikasi. Jilid 1. Edisi Delapan. Edisi Bahasa Indonesia. Jakarta: PT. Prenhallindo (Pearson Asia Education, Pte., Ltd.).

Yuliana, Rahmi. 2012. PERAN KOMUNIKASI DALAM ORGANISASI. Semarang: JURNAL STIE SEMARANG, VOL 4, NO 3, Edisi Oktober 2012. 
